\title{
BMJ Open Recommendations for improving follow-up care for patients with mesothelioma: a qualitative study comprising documentary analysis, interviews and consultation meetings
}

\author{
Catherine Henshall (D) , ${ }^{1}$ Zoe Davey (D) , ${ }^{1}$ Helen Walthall, ${ }^{2}$ Hannah Ball, ${ }^{3}$ \\ Mitra Shahidi, ${ }^{4}$ John Park, ${ }^{5}$ Najib Rahman ${ }^{6}$
}

To cite: Henshall C, Davey Z, Walthall $\mathrm{H}$, et al. Recommendations for improving follow-up care for patients with mesothelioma: a qualitative study comprising documentary analysis, interviews and consultation meetings. BMJ Open 2021;11:e040679. doi:10.1136/ bmjopen-2020-040679

- Prepublication history for this paper is available online To view these files, please visit the journal online (http://dx.doi. org/10.1136/bmjopen-2020040679).

Received 19 May 2020 Revised 19 December 2020 Accepted 07 January 2021

Check for updates

(C) Author(s) (or their employer(s)) 2021. Re-use permitted under CC BY-NC. No commercial re-use. See rights and permissions. Published by BMJ.

For numbered affiliations see end of article.

Correspondence to Dr Catherine Henshall; chenshall@brookes.ac.uk

\section{ABSTRACT}

Objectives The study aim was to explore experiences of patients with pleural mesothelioma of follow-up care in three National Health Service (NHS) Trusts to develop recommendations for practice.

Design The study design was qualitative and comprised three interlinked phases: a documentary analysis, interviews and consultation meetings. Altheide and Johnson's Analytic Realism theoretical framework guided the thematic data analysis process.

Setting The study was conducted in three NHS Trusts in South England. Two were secondary care settings and the third was a tertiary centre.

Participants The secondary care trusts saw 15-20 patients with new mesothelioma per year and the tertiary centre 30-40. The tertiary centre had a designated mesothelioma team. Twenty-one patients met the inclusion criteria: $>18$ years, mesothelioma diagnosis and in followup care. Non-English speaking participants, those unable to provide written informed consent or those whom the clinical team felt would find participation too distressing were excluded. All participants were white, $71 \%$ were $70-79$ years old and $71 \%$ were men. Three consultation meetings were conducted with key stakeholders including mesothelioma nurse specialists, patients with mesothelioma, carers and local clinical commissioning group members.

Main outcome measures Specific outcomes were to gain a detailed understanding of mesothelioma follow-up care pathways and processes and to develop coproduced recommendations for practice.

Results Mesothelioma pathways were not always distinct from lung cancer care pathways. All trusts provided follow-up information and resources but there was varied information on how to access local support groups, research or clinical trial participation. Five themes were developed relating to people; processes; places; purpose and perception of care. Coproduced recommendations for improving mesothelioma follow-up pathways were developed following the consultation meetings.

Conclusions This study has developed recommendations which identify the need for patients with pleural mesothelioma to access consistent, specialist,
Strengths and limitations of this study

- To our knowledge, this is the first study to qualitatively explore experiences of patients with mesothelioma of follow-up care pathways across different hospital trusts; this has enabled comparisons in patient experience to be mapped out and recommendations developed.

- The 21 participants who were interviewed had a wide range of demographic characteristics, increasing the transferability of our findings.

- The consultation meetings undertaken verified and prioritised our study findings, ensuring that any recommendations developed were practical, feasible and of value to patients.

- The recommendations were developed using a coproduction approach, with input from healthcare professionals, patients, carers and commissioners.

streamlined mesothelioma care, centred around specialist mesothelioma nurses and respiratory consultants, with input from the wider multidisciplinary team.

\section{INTRODUCTION}

Malignant pleural mesothelioma is a rare and incurable cancer arising from the pleural lining of the lung. ${ }^{1}$ Its main cause is previous occupational or environmental exposure to asbestos; this has a 20-50 year latency period. ${ }^{2}$ Mesothelioma is a global health concern; however, the UK has the highest recorded incidence of mesothelioma in the world, with 2700 diagnoses per year (approximately 4 cases per 100000$).{ }^{3}{ }^{4}$ Though this number remains relatively small compared with that of lung cancer $(\sim 47000),{ }^{4}$ the symptom burden of mesothelioma is high and is characterised by a poor prognosis and a lack of effective treatments. Median survival is 8-14 months from diagnosis, ${ }^{5}$ with the only 
effective chemotherapy regimen extending this by a median of 2.8 months. ${ }^{6}$ Patients with mesothelioma typically present with advanced disease and progressive symptoms of dyspnoea, chest wall pain, weight loss, sweating and fatigue are common. ${ }^{7-10}$ This results in high levels of psychological distress, including depression, anxiety, fear, anger and hopelessness being frequently documented. ${ }^{810-16}$

Recently published British Thoracic Society guidelines for the investigation and management of malignant pleural mesothelioma recommended that patients with mesothelioma should be offered accurate and understandable information and the opportunity to discuss any concerns about their disease with healthcare professionals, ${ }^{217}$ as a means of facilitating the highest standards of care possible. ${ }^{18} 19$ However, there is a current lack of specialist pleural mesothelioma services to support patients with mesothelioma. Though specialist mesothelioma nurses have been introduced in some areas of the UK, their small number means that their impact is limited as they are unable to reach all patients living with mesothelioma. ${ }^{20}$ In addition, the relatively low numbers of new cases of mesothelioma diagnosed each year ${ }^{3}$ means that patients with mesothelioma often enter the same follow-up pathways as people with lung cancer, despite increasing recognition that their care needs are specific to their condition and that specialist services, such as mesothelioma multidisciplinary teams, can provide real benefit. ${ }^{1-3} 122122$ Little research has been published on the care needs of patients with mesothelioma; however, a systematic review comparing the psychological care needs of patients with mesothelioma and advanced lung cancer ${ }^{12}$ identified a need for separate assessment and care pathways.

Follow-up pathways for patients with mesothelioma differ across UK National Health Service (NHS) Trusts, with variation in the services they offer. The British Thoracic Society guidelines ${ }^{5}$ suggest 3-4 monthly follow-up with an oncologist, respiratory physician or specialist nurse according to individual patients' treatment plans, but no existing national recommendation or published research has specifically examined the follow-up care pathway. As a result, this study set out to explore experiences of patients with pleural mesothelioma of follow-up care in three NHS Trusts in order to develop recommendations for patient follow-up care.

\section{METHODS}

The aim of this study was to explore experiences of patients' with pleural mesothelioma of follow-up care in three NHS Trusts in the South of England. Specific objectives were to gain a detailed understanding of current mesothelioma follow-up care pathways and processes, compare findings across different trusts and to develop recommendations to propose a revised, patient focused, follow-up care service. The study was qualitative in design and comprised three interlinked phases: a documentary analysis, interviews and consultation meetings. Altheide and Johnson's Analytic Realism (1994) theoretical framework was used to guide the data analysis and writing process. This conceptual framework is founded on the view that the social world is an interpreted world and that in order to increase scientific validity, reflexive qualitative research must pay attention to issues such as the research context, interactions between researchers and participants and the perspective through which the research is framed. ${ }^{23}$ These considerations were central to the research process, enabling data to be generated that built understanding of the population under study, while paying attention to the local context in which the research was perceived and understood.

The Consolidated criteria for Reporting Qualitative research 2.0 checklist was adhered to.

\section{Patient and public involvement}

Patients and public involvement (PPI) representatives were involved in the study design process and were invited members of the study's Steering Group Committee. The research questions and outcome measures were reviewed and approved by three PPI representatives, who provided feedback on the original grant application, where aspects of the study design were critiqued, as well as reviewing subsequent study documents, such as participant information leaflets and interview topic guides. PPI members were involved in the conduct of the study throughout, through attendance at three Steering Group meetings (held every 6 months), where issues relating to the study process, including recruitment issues, were debated and agreed. Through the study's consultation meetings, patients and carers also helped to prioritise the research findings, coproduce the study recommendations and help agree plans for dissemination of the findings to the wider mesothelioma community.

\section{Phase 1: documentary analysis of service documents}

Reports, guidance, policy and patient-focused documents relating to mesothelioma follow-up care pathways were accessed by the researchers via mesothelioma or lung cancer nurse specialists at each trust. The documents were manually reviewed by the researchers (ZD, $\mathrm{CH})$, and summarised to establish what services were in place, how they were structured, resourced and managed, as well as identifying any key enablers or barriers to the successful running of the services. Findings were charted using a framework approach to allow comparisons across the three trusts. ${ }^{24}$ Findings from the documentary analysis were used to inform and contextualise phase 2 of the study, allowing the research team to: ask pertinent questions during the interviews that were relevant to the different settings and care pathways in place; identify and interpret nuanced similarities and differences between the three trusts; and develop and refine the framework matrix. 
Phase 2: semistructured interviews with patients with mesothelioma

Individual, face-to-face semistructured interviews with patients with pleural mesothelioma at the participating trusts were conducted by a female, postdoctoral researcher (ZD) with a specialist interest in mesothelioma care, to capture a rich range of perspectives and explore, in depth, their experiences of follow-up care. ${ }^{2526}$ The researcher and participants had not met prior to the interviews and participants had no prior knowledge of the research interviewer. Participants were sampled purposively, according to the hospital trust where they had been treated and by gender to ensure variation in the study population. One of the three participating trusts treated 30-40 patients with new mesothelioma each year, whereas the other two trusts treated 15-20. Therefore, our sampling strategy accounted for this, by recruiting over $50 \%$ of participants from the largest treating site. Based on the maximum number of new cases of mesothelioma across the three trusts totalling 80 , we felt a sample size of 20 would provide us with a sufficient breadth and depth of data to reach saturation. Participants aged 18 years and over, who had been diagnosed with mesothelioma at one of the participating trusts and were in follow-up, were eligible to take part and were recruited by mesothelioma or lung cancer nurse specialists. Patients who were nonEnglish speaking, unable to provide written informed consent, or whom the nurse specialists felt might find participation too distressing, were excluded. Eligible patients were posted an invitation letter, participant information leaflet, and study opt out form. After 2 weeks, any eligible patients who had not opted out were contacted by the researchers and, if they were happy to participate, a time, date and place to carry out the interview was organised, either at participants' own homes or in a private room at the participating university, depending on patient preference. All participants provided written informed consent prior to the interview and completed a short, demographic form. Interviews were guided by an interview topic guide, which explored experiences of patients with mesothelioma of follow-up care, including the type, duration and frequency of support received from healthcare professionals. Satisfaction with care, relationships with healthcare professionals, perceived value of follow-up pathways, challenges or barriers to accessing support and any suggestions for improvement were also explored. Each interview was digitally recorded and lasted approximately 1 hour. Each participant was interviewed once only.

Using Altheide and Johnson's Analytic Realism (1994) theoretical framework to guide the data analysis process, ${ }^{23}$ the interview data were thematically analysed using the framework method to allow assessments and interpretations of the thematic relationships across and within cases to be made. ${ }^{24}$ Data were inputted and managed via Microsoft Excel. All transcripts were coded by a member of the research team $(\mathrm{ZD})$, with three transcripts double coded by two other members of the research team $(\mathrm{CH}, \mathrm{HW})$.
Interview participants were not asked to comment on the interview transcripts. The analytical framework enabled themes to be identified that were derived from the data; these were discussed and agreed by the research team at regular study meetings. Interview findings were presented at the phase 3 consultation meetings.

\section{Phase 3: consultation meetings with stakeholders}

Three consultation meetings with key stakeholders $(n=35)$ : mesothelioma specialist nurses $(n=9)$, patients with mesothelioma and carers $(n=11)$, local clinical commissioning group members, comprising both clinical (respiratory consultants, oncology consultants, clinical nurse specialists) and non-clinical staff $(n=15)$, were held 1-3 months after interview data collection completion to discuss and prioritise the phases 1 and 2 findings. Any overarching themes that had been developed from the interview data were discussed and priority setting activities were undertaken to examine their relevance and importance to patients. Each consultation meeting lasted 1-3 hours; refreshments were provided and travel expenses were reimbursed. Over the course of the meetings coproduced recommendations for policy and practice were developed between the researchers and the stakeholders. Key discussion points were charted using a framework approach to allow the priorities of stakeholders to be compared and recommendations to be drafted. This enabled a preferred, patient focused, mesothelioma follow-up service to be proposed that was underpinned by a rigorous evidence base, as well as being collaborative and inclusive of the needs and priorities of patients with mesothelioma.

\section{RESULTS}

\section{Documentary analysis}

Each trust had clearly defined mesothelioma treatment and follow-up pathways in place (table 1).

However, these pathways were not always distinct from the lung cancer care pathway. One trust had established a regional mesothelioma multidisciplinary team meeting in addition to its regular lung cancer multidisciplinary team meeting, but attendance at this meeting was variable. A wide range of healthcare professionals were involved in the mesothelioma care pathways at each trust; however, there was variation with regard to whether patient care was led by respiratory or oncology teams. In addition, only one trust had a mesothelioma specialist nurse based on site. Although the mesothelioma specialist nurse covered all three trusts, the majority of their caseload fell under the trust at which they were based. All trusts provided patient information packs to patients which included leaflets about mesothelioma, details of key contacts and an asbestos disease support charity that provided assistance with accessing benefits and entitlements. Across the trusts there was variation in the level of information provided to patients about research and clinical trials, as well as how to access local support groups. Two of the trusts treated 


\begin{tabular}{|c|c|c|c|}
\hline & Trust A & Trust B & Trust C \\
\hline Type of hospital/trust & District general hospital & Tertiary centre & District general hospital \\
\hline Clinical team & $\begin{array}{l}\text { Lung cancer MDT: } \\
\text { respiratory, oncology, thoracic, } \\
\text { palliative, radiology, pathology, } \\
\text { lung cancer CNS }\end{array}$ & $\begin{array}{l}\text { Lung cancer MDT and regional } \\
\text { mesothelioma MDT: } \\
\text { pleural/respiratory, oncology, } \\
\text { thoracic, palliative, radiology, } \\
\text { pathology, lung cancer CNS, } \\
\text { mesothelioma specialist nurse }\end{array}$ & $\begin{array}{l}\text { Lung cancer MDT: } \\
\text { respiratory, oncology, thoracic, } \\
\text { lung cancer CNS, pleural nurse }\end{array}$ \\
\hline Pathway & $\begin{array}{l}\text { Oncology led } \\
6-8 \text { weekly follow-up } \\
\text { If treatment discontinued referral } \\
\text { to community/palliative care }\end{array}$ & $\begin{array}{l}\text { Respiratory led } \\
2-3 \text { monthly follow-up } \\
\text { depending on symptom control }\end{array}$ & $\begin{array}{l}\text { Oncology led } \\
\text { Monthly follow-up } \\
\text { If treatment discontinued } \\
\text { referral to community/palliative } \\
\text { care }\end{array}$ \\
\hline
\end{tabular}

CNS, Clinical Nurse Specialist; MDT, multi-disciplinary team.

15-20 newly diagnosed patients per year, while the third treated 30-40 per year; all trusts covered large geographical areas and had primary and satellite clinic sites for patient treatment and follow-up visits.

\section{Interviews}

The demographic characteristics of participants are presented in table 2 .

Thirty-two eligible patients agreed to be contacted by the research team, the majority of which came from the tertiary centre $(n=20)$. Of these, 21 consented to take part in the interview, nine declined, one was too unwell to participate and one had died; this was sufficient to reach data saturation. The majority of participants were white, male, aged 70-79 and had received their diagnosis within the last 18 months. Most participants had received chemotherapy and/or surgery $(n=17,81.0 \%)$; however, two $(9.5 \%)$ reported not receiving any treatment or support, and two $(9.5 \%)$ reported receiving symptomatic support only.

Thematic analysis identified five overarching themes relating to patients' experiences and views of follow-up care services: People, Process, Place, Purpose and Perception of Care. The first four themes aligned with distinct aspects of the follow-up care pathway and were weighted differently by participants in terms of their importance and the impact they had on their overall perception of care. Thus, the final, fifth theme 'Perception of Care' underpins the first four themes and represents the extent to which the accumulation of these themes impacts on patients with mesothelioma perceived quality and satisfaction with follow-up care. The five themes are expanded on below, with relevant, illustrative quotes presented in table 3 .

People

Participants identified the relationships they developed with healthcare professionals throughout their diagnosis and treatment as being central to their experience and level of trust they had in their follow-up care provision. Open communication and continuity of care, particularly with specialist nurses and lead consultants, were particularly important; having a named clinician, seeing the same clinicians at each appointment and having sufficient consultation time were viewed as key to this. The role of family and friends in providing additional practical and emotional support throughout the care pathway was also illuminated. Participants varied with regard to their willingness to engage with support groups and their associated benefits. However, participants who did belong to support groups perceived them to be important sources of support.

\section{Process}

Across the trusts, participants were generally satisfied with the clinical environment they were cared for in. They commented that efficient, flexible processes associated with automated and routine systems, such as appointment 


\begin{tabular}{|c|c|}
\hline Domain & $\mathbf{N}(\%)$ \\
\hline \multicolumn{2}{|l|}{ Gender } \\
\hline Male & $15(71.4)$ \\
\hline Female & $6(28.6)$ \\
\hline \multicolumn{2}{|l|}{ Age group (years) } \\
\hline $60-69$ & $2(9.5)$ \\
\hline $70-79$ & $15(71.4)$ \\
\hline $80-89$ & $4(19.0)$ \\
\hline \multicolumn{2}{|l|}{ Ethnic group } \\
\hline White & $21(100)$ \\
\hline \multicolumn{2}{|l|}{ NHS Trust } \\
\hline Trust A & $6(28.6)$ \\
\hline Trust B & $11(52.4)$ \\
\hline Trust C & 4 (19.0) \\
\hline \multicolumn{2}{|c|}{ Time since diagnosis (months) } \\
\hline $1-6$ & $4(19.0)$ \\
\hline $7-12$ & $4(19.0)$ \\
\hline $13-18$ & $5(23.8)$ \\
\hline $19-24$ & $1(4.8)$ \\
\hline $25-29$ & $1(4.8)$ \\
\hline $30-36$ & $0(0)$ \\
\hline$>36$ & $6(28.6)$ \\
\hline \multicolumn{2}{|l|}{ Treatment* } \\
\hline Chemotherapy & $12(57.1)$ \\
\hline Radiotherapy & $5(23.8)$ \\
\hline Surgery & $9(42.9)$ \\
\hline Immunotherapy & $2(9.5)$ \\
\hline Symptom support & $8(38.1)$ \\
\hline Psychological support & $2(9.5)$ \\
\hline Hospice care & $1(4.8)$ \\
\hline Research trial & $2(9.5)$ \\
\hline None & $2(9.5)$ \\
\hline
\end{tabular}

NHS, National Health Service .

booking, waiting times, telephone helplines, routine scans and tests and moving between and across services, helped make the follow-up care pathway easier to navigate and more responsive to their individual needs and circumstances. However, when administrative or procedural errors occurred, some participants reported distress.

\section{Place}

Practical and logistical factors associated with hospital and clinic locations, parking and access were identified as causing potential frustration or distress. However, despite often being irritated with these issues, most participants accepted that these problems were not specific to their mesothelioma care pathway; therefore, they did not substantially impact on their overall perception of care.

\section{Purpose}

Participants identified a number of key care priorities and informational needs that were highly motivating factors for engaging with follow-up care. The main driver was a desire to monitor disease progression and symptom management, something which led to a desire for regular follow-up consultations with care teams. Equally, discussions around treatment options, whether to continue with treatment and when to seek out new, private and/ or experimental treatments were important markers within the follow-up trajectory and the ease with which these were discussed was linked closely to the level of trust participants had in their care team. Follow-up care was also associated with a desire to gain more information about mesothelioma in terms of prognosis, care pathways, benefits and entitlements and any planned transitions to linked services such as community and palliative care teams. Participants reported variations in their baseline knowledge of mesothelioma and the subsequent level of information they were provided with from their care teams.

\section{Perception of care}

Overall, most participants viewed the treatment and follow-up care they had received for mesothelioma positively. Generally, participants who reported the most consistent healthcare contacts also reported high levels of trust in their named consultant and specialist nurse, and a resulting satisfaction with care. This level of trust also impacted on the treatment choices of some participants, with those who described less trusting relationships being more likely to seek second opinions, or treatments from alternative NHS providers and the private sector. However, some participants who reported suboptimal care were less confident or unaware of the other options available to them, such as how to access advice and support from a specialist mesothelioma nurse.

\section{Consultation meetings}

The findings that emerged from the interview data were reviewed at the consultation meetings and barriers, facilitators and potential solutions to any challenges identified were discussed and prioritised, in relation to the overall perceived impact on care (table 4 ).

From this, a draft set of recommendations were developed in relation to the preferred structure of the clinical care team, the timing and content of information provided to patients, the integration of secondary, palliative and community care services, and links with wider support services. The full set of recommendations will be reported elsewhere, but figure 1 sets out the six main recommendations arising from the consultation meetings. The primary recommendation was for all patients with mesothelioma to have access to a specialist mesothelioma team within a streamlined mesothelioma care 
Table 3 Key themes and illustrative quotes from interviews

\begin{tabular}{|c|c|c|}
\hline Theme & Subtheme & Quotation \\
\hline \multirow[t]{4}{*}{ People } & Communication & $\begin{array}{l}\text { The reason those Meso nurses are there is they have got the time to learn more about it } \\
\text { and keep [us] on track with what's going on (Male, 60-69, Trust B) }\end{array}$ \\
\hline & Continuity of care & $\begin{array}{l}\text { I don't feel as though l've been cast off. It's obviously going to be a different kind of } \\
\text { approach [in palliative care] but...we've still got that link with [the consultant and the } \\
\text { Specialist Nurses] (Female, 70-79, Trust A) }\end{array}$ \\
\hline & Family and friends & $\begin{array}{l}\text { I don't know how people could cope, really. If there was no family around and I was the } \\
\text { way I was now, I still don't think I'd be the same person (Male, } 70-79 \text {, Trust A) }\end{array}$ \\
\hline & Support groups & $\begin{array}{l}\text { (We went] to find out more about it and...how other people are dealing with it. And that } \\
\text { was so important (Female, } 70-79 \text {, Trust A) }\end{array}$ \\
\hline \multirow[t]{4}{*}{ Process } & Administration & $\begin{array}{l}\text { The professionals have been very good, the surgeon and the registrar and other people } \\
\text { that l've seen...It's admin that really drives me crazy. (Male, } 70-79 \text {, Trust A) }\end{array}$ \\
\hline & Accessibility & $\begin{array}{l}\text { We need to have a phone number where we can make the call when it's necessary. And } \\
\text { we know that help is available. (Male, } 70-79 \text {, Trust A) }\end{array}$ \\
\hline & Delays & $\begin{array}{l}\text { Scanxiety, when you get anxious after you've had a scan what the results are...there is, } \\
\text { unfortunately a general delay across the whole board (Male, 60-69, Trust B) }\end{array}$ \\
\hline & $\begin{array}{l}\text { Falling through the } \\
\text { system }\end{array}$ & $\begin{array}{l}\text { You fell in a bit of a crack for a while, because, although with oncology we declined it... } \\
\text { but somehow we hadn't got it back respiratory care. (Female, } 70-79 \text {, Trust C) }\end{array}$ \\
\hline Place & $\begin{array}{l}\text { Distance, location, } \\
\text { parking }\end{array}$ & $\begin{array}{l}\text { I don't drive. Well, friends have said l'll take you, but of course, they're all about my age } \\
\text { and they might have problems of their own (Female, } 70-79 \text {, Trust A) }\end{array}$ \\
\hline \multirow[t]{6}{*}{ Purpose } & Monitoring & $\begin{array}{l}\text { I've got peace of mind, knowing that every so many weeks I'm going to see the } \\
\text { consultant and they can monitor the progress and that's all I really need... How it's } \\
\text { progressing... How to deal with the pain when the time comes" (Male 70-79, Trust A) }\end{array}$ \\
\hline & $\begin{array}{l}\text { Treatment options/ } \\
\text { decisions }\end{array}$ & $\begin{array}{l}\text { l'd always try those things [treatments]...You've got to...Because there's always } \\
\text { something new coming out and that's what you bank on...That's what you've got to hope } \\
\text { for all the time and just go with whatever's going." (Male, 70-79, Trust B) }\end{array}$ \\
\hline & $\begin{array}{l}\text { Understanding } \\
\text { mesothelioma }\end{array}$ & $\begin{array}{l}\text { The horrible thing is that there's going to come a point when I may start to go. You don't } \\
\text { even know the process of dying from this disease. Is it sudden? Or is it progressive? I } \\
\text { don't think anybody can [tell me]." (Male, 70-79, Trust A) }\end{array}$ \\
\hline & $\begin{array}{l}\text { Understanding } \\
\text { pathways }\end{array}$ & $\begin{array}{l}\text { I'm perfectly realistic. I know l'm going to die. I just want some sort of realistic } \\
\text { understanding...that I'm living by myself. I'm } 75 \text { years old...The hospice group who have } \\
\text { been extremely good, they don't have accommodation. (Male, 70-79, Trust A) }\end{array}$ \\
\hline & $\begin{array}{l}\text { Understanding } \\
\text { benefits and } \\
\text { entitlements }\end{array}$ & $\begin{array}{l}\text { Once I was diagnosed, I was immediately put in touch with a charity...They were very, } \\
\text { very helpful...looking into benefits...compensation....solicitors...They....know the system, } \\
\text { so that helps. (Male, 60-69, Trust B) }\end{array}$ \\
\hline & Health literacy & $\begin{array}{l}\text { We know how to use information...A lot of people... Could be treated without actually } \\
\text { having the ability to say, what's going on? (Male, } 70-79 \text {, Trust C) }\end{array}$ \\
\hline \multirow[t]{3}{*}{$\begin{array}{l}\text { Perception of } \\
\text { care }\end{array}$} & Satisfaction & $\begin{array}{l}\text { I've been very satisfied with the team...They've been very good to me...The follow-up } \\
\text { care that l've had...They've kept an eye on me. (Male, } 80-89 \text {, Trust B) }\end{array}$ \\
\hline & Trust & $\begin{array}{l}\text { We trusted [the consultant] implicitly that if there was [another treatment option], they } \\
\text { would have said. (Female, } 70-79 \text {, Trust A) }\end{array}$ \\
\hline & Second opinions & $\begin{array}{l}\text { You won't get the help, once you've had the allowed treatment... You have to find it } \\
\text { somewhere else...Literally, find a trial or sometimes I understand some of the more } \\
\text { specialist trusts...trying to find new solutions. (Male, } 60-69 \text {, Trust B) }\end{array}$ \\
\hline
\end{tabular}

pathway. The recommendations also led to the conceptual development of our 'pyramid of care' (figure 2), following input from the key stakeholders. The pyramid of care identifies the core support structures required to develop and sustain a robust and streamlined mesothelioma care pathway. The pyramid of care places a named mesothelioma specialist nurse and mesothelioma specialist respiratory consultant at the top of the pyramid, underpinned by expertise and resource from the wider multidisciplinary team. It emphasises the importance of iterative communication channels between different clinical and support services to promote patient centred, joined up care.

\section{DISCUSSION}

Our findings and newly developed recommendations have illuminated the need for patients with 
Table 4 Needs, barriers and solutions identified through consultation meetings

\begin{tabular}{|c|c|c|c|c|}
\hline Themes 1-4 & Need & Barriers & Solution & care (Theme 5) \\
\hline People & $\begin{array}{l}\text { Early access to } \\
\text { mesothelioma specialist } \\
\text { team } \\
\text { Continuity of care and } \\
\text { integrated respiratory and } \\
\text { follow-up pathways }\end{array}$ & $\begin{array}{l}\text { Lack of resources } \\
\text { Existing organisational } \\
\text { structures and referral } \\
\text { processes } \\
\text { Lack of patient knowledge } \\
\text { of pathway }\end{array}$ & $\begin{array}{l}\text { Invest in mesothelioma } \\
\text { specialist nurses } \\
\text { Introduce mesothelioma } \\
\text { specialist consultants } \\
\text { Train lung CNSs } \\
\text { Shared care approach with } \\
\text { respiratory led follow-up }\end{array}$ & High \\
\hline Process & $\begin{array}{l}\text { Joined up service provision } \\
\text { between secondary, } \\
\text { community and palliative } \\
\text { care } \\
\text { Clear communication } \\
\text { processes within Trusts } \\
\text { Continuity of care when } \\
\text { transferring in and out of } \\
\text { different services }\end{array}$ & $\begin{array}{l}\text { Differences in referral } \\
\text { pathways and accessing } \\
\text { palliative care/community } \\
\text { services } \\
\text { Lack of resources } \\
\text { Patient awareness } \\
\text { of services available } \\
\text { at different trusts } \\
\text { Administrative issues }\end{array}$ & $\begin{array}{l}\text { Mesothelioma specialist } \\
\text { nurse primary point of contact } \\
\text { between secondary, palliative } \\
\text { and community care } \\
\text { Patients provided with options } \\
\text { for contact and communication } \\
\text { Continuous contact with } \\
\text { mesothelioma specialist nurse } \\
\text { throughout pathway }\end{array}$ & Medium \\
\hline
\end{tabular}

mesothelioma to have access to a specialist, streamlined mesothelioma care pathway, to ensure the delivery of consistent, patient centred care. While this provision of care should be centred around, where possible, mesothelioma specialist nurses and respiratory consultants, input from multidisciplinary team members is essential for underpinning the patient follow-up pathway with appropriate resources which can be accessed from the point of diagnosis onwards, to promote joined up care (figure 2). The benefits of being able to access a specialist

\begin{tabular}{|l} 
A Ensure that all mesothelioma patients have access to a specialist mesothelioma team within a \\
streamlined mesothelioma care pathway \\
B Ensure that information regarding diagnosis, prognosis, and follow-up care is provided in a supportive, \\
timely and appropriate environment \\
C Ensure patients are equipped with the necessary information to guide their decision making with \\
regard to treatment and care pathways \\
D Ensure the streamlined integration between secondary care, palliative care and community care \\
services \\
Ensure patients are provided with appropriate information resources from the point of diagnosis, \\
throughout their care pathway \\
F Facilitate personalised links between secondary care and wider support services
\end{tabular}

Figure 1 Key recommendations for follow. 


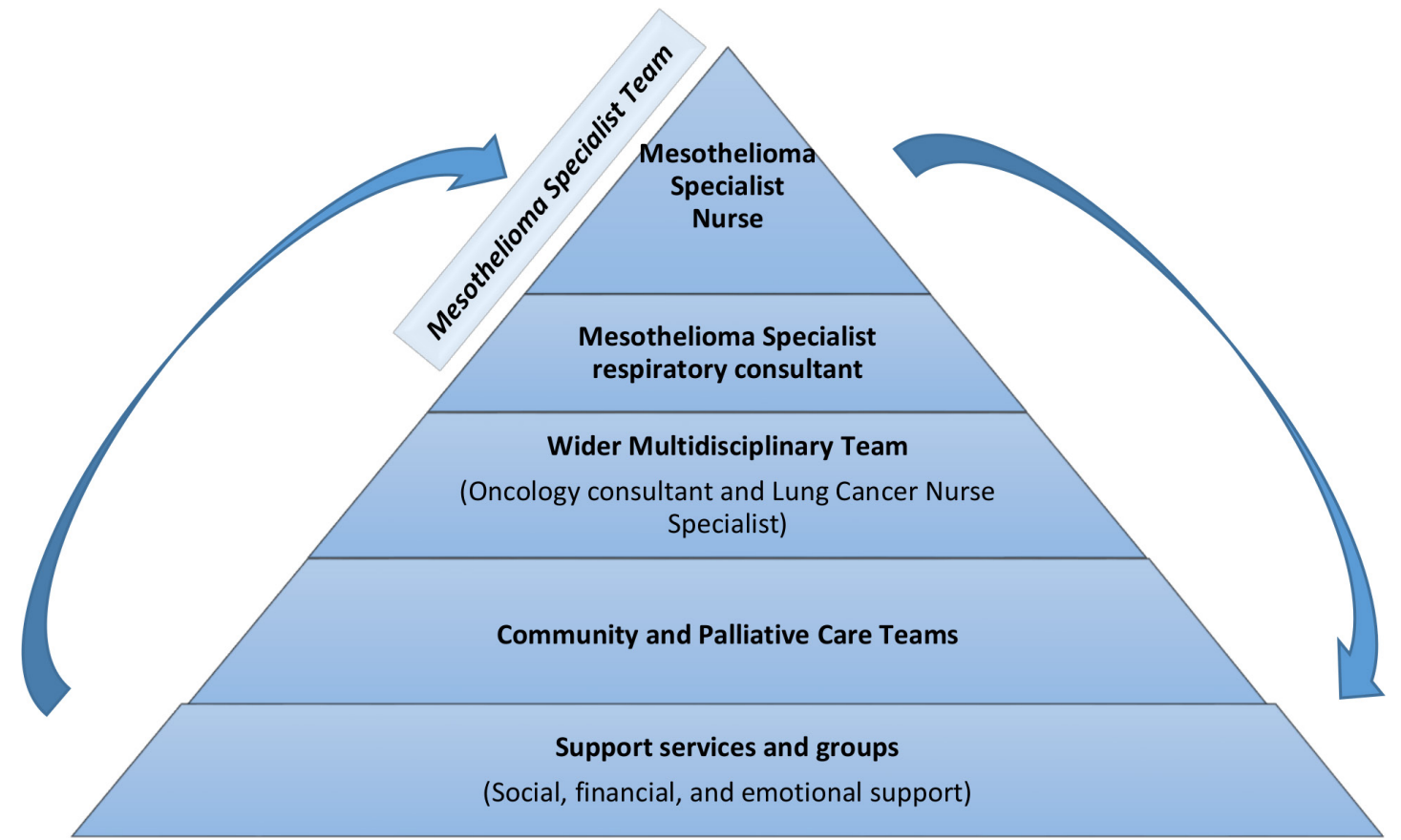

Figure 2 Mesothelioma 'pyramid of care' patient support structure.

mesothelioma team have clear advantages for patients. For example, rapid and appropriate access to interventions, such as the insertion of indwelling catheters and targeted pain management, can help alleviate symptoms caused by pleural effusions and empyema. Addressing these long-term symptomatic management and palliative care concerns is something that can be anticipated and effectively resolved through close working with respiratory consultants who have expertise in this area, alongside comprehensive follow-up support and monitoring from mesothelioma specialist nurses. However, when this is not feasible, oncology led or formalised shared care approaches should also be considered.

Additionally, the current limited mesothelioma specialist nurse resource ${ }^{20}$ highlights the need for appropriate training and education to be provided to lung cancer nurse specialists, palliative and community care teams by mesothelioma specialist nurses, to ensure needs and requirements of patients with mesothelioma are being met consistently and comprehensively throughout their follow-up pathway.

In line with British Thoracic Society guidelines, ${ }^{2} 17$ patients with mesothelioma must be equipped with necessary levels of information, including accessing clinical trials opportunities, to inform their decision-making. Currently, across different hospital trusts, patients are exposed to variation in the type, level and range of information that is provided to them, resulting in an inequity of opportunity around care and treatment provision. While there may be variations in patients' health literacy and information seeking, ${ }^{27}$ clinicians must assess understanding, as well as the level and type of information that individual patients wish to receive. This may be facilitated through the presence of a mesothelioma/lung cancer specialist nurse in follow-up consultations.

The omnipresent concerns expressed by patients with pleural mesothelioma about their future health and how it will be managed can be mediated through the provision of regular follow-up consultations with a named care team. The frequency of these consultations may vary depending on patient need, symptom severity and prognosis, but should be reviewed regularly in line with patient care priorities. Similarly, early referral to palliative care services, along with the provision of a clear rationale as to why it is necessary may help to assuage feelings of uncertainty. An iterative relationship between secondary, palliative and community care services should be maintained to aid communication and specialist support at all levels.

A key study strength is that, to our knowledge, it is the first to explore, in depth, experiences of patients with pleural mesothelioma of follow-up care pathways across different hospital trusts with different organisational systems and processes. This has enabled comparisons in patient experience to be mapped out and recommendations developed. The twenty-one interview participants had a wide range of demographic characteristics, increasing the transferability of our findings, while the consultation meetings undertaken verified and prioritised these findings, ensuring that any recommendations developed were practical, feasible and of value to patients. A study limitation is that although the participant population was representative of the wider mesothelioma population in terms of age, ethnicity and gender, six interview participants (29\%) had been diagnosed with mesothelioma over 36 months previously, which is substantially longer than the median survival time of 8-14 months. Moreover, a substantially higher proportion of participants 
in this study received a form of active treatment $(81 \%)$ than was found in the most recent National Mesothelioma Audit $(48 \%) .{ }^{19}$ The high levels of patient satisfaction identified in the current study may in part be attributable to the higher level of specialist care received by this group.

Little literature exists on the patient experience of mesothelioma follow-up care ${ }^{12}$ However, there is growing interest in this area, with the recent Mesothelioma Outcomes Research and Experience (MORE) survey collecting patient with mesothelioma data about what can be done to enhance the patient experience. ${ }^{5}$ In addition, a phenomenological study exploring the lived experience of people with mesothelioma found that the communication pathways between patients and healthcare providers were central to the patient experience ${ }^{11}$; this correlates strongly with our findings. However, Walker's study was based in the USA, whereas our study examined the UK healthcare system, focusing on the role of mesothelioma specialist care teams and offering practical solutions for optimising care outcomes.

Our findings have important implications for clinicians and policy-makers and have led to a number of recommendations being produced. Clinicians must consider what changes to practice can be made within their organisations to facilitate them, something that will require close working with other sectors of the health service. Policy-makers need to consider how resources can be optimised and restructured to ensure that a bespoke mesothelioma care pathway is realised within secondary care services. This may mean lobbying to improve the support structures and services available to patients (figure 2) and ensuring that they have access to the full range of treatment options available, regardless of the location of their care.

Our study has illuminated many important questions relating to how patients with pleural mesothelioma experience care and has highlighted the need for consistent input from clinical teams. However, only a relatively small number of patients with mesothelioma are seen by respiratory and oncology teams each year, compared with patients with lung cancer and this may impact on the extent to which clinicians use the evidence base to inform their treatment decision-making. Other factors such as prior experience, advice from colleagues, adhering to the status quo and input from the multidisciplinary team may be influencing factors. Future research to unpick these decision-making processes would help ensure that the patient experience is underpinned by a rigorous, and consistently upheld, evidence base.

\section{Author affiliations}

${ }^{1}$ Faculty of Health and Life Sciences, Oxford Brookes University, Oxford, UK

${ }^{2}$ Nursing and Midwifery Research and Innovation, Oxford University Hospitals NHS

Foundation Trust, Oxford, UK

${ }^{3}$ Cancer Services, Oxford University Hospitals NHS Foundation Trust, Oxford, UK

${ }^{4}$ Respiratory Medicine, Buckinghamshire Healthcare NHS Trust, Amersham, UK

${ }^{5}$ Respiratory Medicine, Royal Berkshire NHS Foundation Trust, Reading, UK

${ }^{6}$ Oxford Centre for Respiratory Medicine, Oxford University, Oxford, UK

Twitter Catherine Henshall @cathy_henshall
Acknowledgements We would like to thank the study participants, including patients, carers and healthcare professionals, who gave up their time to participate in this study. CH is a National Institute for Health Research (NIHR) Senior Nurse and Midwife Research Leader and also acknowledges the support of the NIHR Oxford cognitive health Clinical Research Facility. NMR is funded by the Oxford NIHR Biomedical Research Centre.

Contributors All authors made substantial contributions to the conception or design of the work; or the acquisition, analysis, or interpretation of data for the work and were involved in drafting the work or revising it critically for important intellectual content. All authors gave final approval of the version to be published and have agreed to be accountable for all aspects of the work in ensuring that questions related to the accuracy or integrity of any part of the work are appropriately investigated and resolved. The corresponding author attests that all listed authors meet authorship criteria and that no others meeting the criteria have been omitted. CH was responsible for the original study design and conception, was involved in the data analysis process and the overall coordination and management of the study. She was also responsible for collating the first draft of the paper and, as guarantor, is responsible for the overall content. ZD led on the data collection and analysis and contributed to the first draft of the paper. NR, MS, JP, HB and $\mathrm{HW}$ all contributed to the study design and development and were involved in the analysis and/or interpretation of the study data. All contributed to either the drafting or critically reviewing the manuscript. We would like to acknowledge the important contributions of the patient and carers who contributed to the study, either through their participation or through their engagement in the study design and development process.

Funding The study was funded by Mesothelioma UK (Nurse Research Fund). The funder was not involved in the study design or study process but were involved in the decision to submit the article for publication. The researchers confirm independence from the funders and all the authors confirm that they had full access to all of the data in the study and take responsibility for the integrity of the data and the accuracy of the data analysis.

Disclaimer The views expressed in this article are those of the author(s) and not necessarily those of the NIHR, or the Department of Health and Social Care.

Competing interests HB is part funded by Mesothelioma UK as a mesothelioma nurse specialist.

Patient and public involvement Patients and/or the public were involved in the design, or conduct, or reporting, or dissemination plans of this research. Refer to the Methods section for further details.

Patient consent for publication Not required.

Ethics approval The study was reviewed and approved by the 0xford Brookes University Research Ethics Committees (L18170 and FREC 2018/10), the NHS Health Research Authority (19/WM/0022), and the participating trusts' local research and development departments. All participants provided written informed consent prior to taking part in the study.

Provenance and peer review Not commissioned; externally peer reviewed.

Data availability statement Data are available on reasonable request from the corresponding author $(\mathrm{CH})$ (chenshall@brookes.ac.uk) and comprises deidentified interview data from participants.

Open access This is an open access article distributed in accordance with the Creative Commons Attribution Non Commercial (CC BY-NC 4.0) license, which permits others to distribute, remix, adapt, build upon this work non-commercially, and license their derivative works on different terms, provided the original work is properly cited, appropriate credit is given, any changes made indicated, and the use is non-commercial. See: http://creativecommons.org/licenses/by-nc/4.0/.

\section{ORCID iDs}

Catherine Henshall http://orcid.org/0000-0001-5659-3296

Zoe Davey http://orcid.org/0000-0002-4583-3714

\section{REFERENCES}

1 Bibby AC, Tsim S, Kanellakis N, et al. Malignant pleural mesothelioma: an update on investigation, diagnosis and treatment. Eur Respir Rev 2016;25:472-86.

2 Woolhouse I, Bishop L, Darlison L, et al. British thoracic Society guideline for the investigation and management of malignant pleural mesothelioma. Thorax 2018;73:11-30. 
3 Royal College of Physicians. National mesothelioma audit: organisational audit report 2019. London; 2020.

4 Cancer Research UK. Statistics by cancer type, 2019. Available: https://www.cancerresearchuk.org/health-professional/cancerstatistics/statistics-by-cancer-type

5 Scherpereel A, Astoul P, Baas P, et al. Guidelines of the European respiratory Society and the European Society of thoracic surgeons for the management of malignant pleural mesothelioma. Eur Respir $J$ 2010;35:479-95.

6 Vogelzang NJ, Rusthoven JJ, Symanowski J, et al. Phase III study of pemetrexed in combination with cisplatin versus cisplatin alone in patients with malignant pleural mesothelioma. J Clin Oncol 2003;21:2636-44.

7 Pistolesi M, Rusthoven J. Malignant pleural mesothelioma: update, current management, and newer therapeutic strategies. Chest 2004;126:1318-29.

8 Chapman E, Hughes D, Landy A, et al. Challenging the representations of cancer pain: experiences of a multidisciplinary pain management group in a palliative care unit. Pall Supp Care 2005;3:43-9.

9 Cordes ME, Brueggen C. Diffuse malignant pleural mesothelioma: Part II. symptom management. Clin J Oncol Nurs 2003;7:545-52.

10 Clayson H, Seymour J, Noble B. Mesothelioma from the patient's perspective. Hematol Oncol Clin North Am 2005;19:1175-90.

11 Walker SL, Crist JD, Shea K, et al. The lived experience of persons with malignant pleural mesothelioma in the United States. Cancer Nurs 2019; Publish Ahead of Print.

12 Ball H, Moore S, Leary A. A systematic literature review comparing the psychological care needs of patients with mesothelioma and advanced lung cancer. Eur J Oncol Nurs 2016;25:62-7.

13 Lebovits AH, Chahinian AP, Gorzynski JG. Psychological aspects of asbestos-related mesothelioma and knowledge of high risk for cancer cancer detection and prevention. Cancer Detect Prev $1981 ; 4: 181-4$.
14 Clayson H. Suffering in mesothelioma: concepts and contexts. Prog Palliat Care 2003;11:251-5.

15 Hughes N, Arber A. The lived experience of patients with pleural mesothelioma. Int J Palliat Nurs 2008;14:66-71.

16 British Lung Foundation. Survey of mesothelioma patients and their carers. London; 2009.

17 Woolhouse I, Bishop L, Darlison L, et al. BTS guideline for the investigation and management of malignant pleural mesothelioma. BMJ Open Respir Res 2018;5:e000266.

18 Royal College of Physicians. National lung cancer audit. Pleural mesothelioma report 2016. Available: https://www.rcplondon.ac.uk/ projects/outputs/national-lung-cancer-audit-pleural-mesotheliomareport-2016-audit-period-2014

19 Royal College of Physicians. National mesothelioma audit report 2020 (for the audit period 2016-18). London RCP; 2020.

20 Darlison L, Mckinley D, Moore S. Findings from the National mesothelioma experience survey. Cancer Nursing Practice 2014;13:32-8.

21 Darlison L. Improving mesothelioma services. Lung Cancer in Practice 2008;5:10-11.

22 Department of Health. Mesothelioma framework. Norwich; 2007.

23 Altheide D, Johnson J. Criteria for assessing interpretive validity in qualitative research. In: Denzin N, Lincoln Y, eds. Handbook of qualitative research. Thousand Oaks, CA: Sage, 1994: 485-99.

24 Gale NK, Heath G, Cameron E, et al. Using the framework method for the analysis of qualitative data in multi-disciplinary health research. BMC Med Res Methodol 2013;13:117.

25 Gill P, Stewart K, Treasure E. Methods of data collection in qualitative research. BDJ 2008;204:291-5.

26 Mason J. Qualitative researching. London: Sage, 2002.

27 Greenhalgh T. Health literacy: towards system level solutions. BMJ 2015;350:h1026. 